\title{
La hora de las elecciones en Panamá
}

Guillermo Castro Herrera*

$\mathrm{L}$

a hora de las elecciones ha llevado a Panamá al proceso más amplio y complejo de la formación del Estado naçional en el marco de las peculiares relaciones de dependencia impuestas a este país por el imperialismo norteamericano desde su independencia en 1903. Enfocado en estos términos el problema, se hace necesario examinarlo en dos direcciones diferentes. Una tiene que ver con el papel de los procesos electorales como factores de legitimación en el proceso de formación mencionado; la otra, con las circunstancias que-entre 1984 y 1989-bloquearon la posibilidad de cumplimiento de ese

- El Día Latinoamericano. papel en dos elecciones sucesivas y abrieron paso a la escalada intervencionista norteamericana que culminó con la invasión y el golpe de Estado del 20 de diciembre de ese último año, ejecutados por las fuerzas armadas de Estados Unidos.

El doble examen del que hablamos no puede restringirse, como es evidente, a los hechos que precedieron o siguieron a la invasión. Ella misma, por el contrario, se inscribe y se explica dentro de un marco histórico mucho más amplio y complejo que los azares de la carrera político-militar de Manuel Antonio Noriega, o los del empeño de George Bush por demostrar a sus conciudadanos que no merece la fama de hombre indeciso 
y estrecho de miras que lo precedió a su llegada a la Casa Blanca. No son las coyunturas, en efecto, las que iluminan el sentido de la historia, sino al revés, y de lo que se trata es precisamente de recuperar ese sentido, si se quiere actuar con alguna eficacia sobre el curso de los acontecimientos que en él se expresan.

La historia de que se trata, en este caso, es la del proceso de formación de la sociedad panameña a lo largo del siglo XX, que incluye por necesidad la de los conflictos que dicho proceso ha supuesto y supone para las relaciones entre Panamá y Estados Unidos. A este respecto cabe recordar que tal conflicto entre naciones sólo puede ser realmente comprendido si se lo considera, al propio tiempo, como conflicto entre sociedades y-sobretodo-con Estados Unidos. Esto, en el caso de Panamá, se ha expresado en los objetivos, los términos y los límites con que los sectores fundamentales de la sociedad panameña han encarado el próblema de la construcción del Estado nacional y de las relaciones entre éste y el norteamericano.

Tal problema, como se sabe, ha estado y está estrechamente vinculado al de la plena recuperación por parte de Panamá, de su derecho soberano al usufructo de su posición geográfica y de la infraestructura construida por el Estado norteamericano-y administrada por éste desde 1903, en su carácter de "capitalista colectivo ideal", en función de los intereses económicos y de seguridad de su sociedad-, para hacer posible el tránsito marítimo entre los océanos Atlántico y Pacífico. Debe recordarse, al respecto, que el canal de Panamá es el único enclave de capital monopólico del Estado norteamericano existente en América Latina, y que tal enclave depende en primer término del Departamento de Defensa de aquel país. De ello se des- prende, asi, que toda reivindicación panameña sobre el canal, sus actividades y sus instalaciones productivas y militares enfrenta a Panamá directamente con el conjunto del Estado norteamericano antes que con uno u otro de los grupos fundamentales de poder económico y político de aquel país.

Pero de ello se desprende, también, que el desarrollo del Estado nacional panameño ha ocurrido en el marco por demás complejo de las articulaciones entre ese enclave -concebido, organizado y administrado en función de las formas más avanzadas de la economía capitalista-, y una formación económicosocial dependiente, en cuya base material han predominado las formas más atrasadas e improductivas del capitalismo. Tal articulación ha dado lugar a que la presencia del enclavefavorezca el desarrollo en Panamá de aquellas ramas, formas y estructuras de actividad económica complementarias de la función que la economía norteamericana le asigna en la división internacional del trabajo, bloqueando y mediatizando el desarrollo de aquellas otras de las que depende en última instancia la posibilidad de que la sociedad panameña pueda construir la base material imprescindible para su democracia, su autodeterminación y su soberanía.

Considerada en términos políticos, esta situación permite entender la estrecha relación existente a todo lo largo de la historia de Panamá entre las reivindicaciones nacionales frente al Estado norteamericano, por un lado, y las de la propia sociedad panameña frente a su Estado nacional, por otro, incluyendo en estas últimas las correspondientes a la democracia y al papel que en ellas toca cumplir a los procesos electorales. En lo que toca a estas relaciones entre la sociedad y el Estado en Panamá, puede 
afirmarse por otra parte que éstas han discurrido a lo largo del siglo en torno al enfrentamiento entre una minoría oligárquica-que desde el nacimiento de la república controla lo fundamental del poder económico y político del país, en connivencia con el Estado y el gran capital transnacional norteamericanos-, y amplios sectores nacionales intęgrados portrabajadores de la ciudad y el campo, pequeños y medianos propietarios y fracciones de capas medias que cuestionan esa hegemonía oligárquica -por su carácter antipopular-, y esa relación de dependencia -por su carácter hostil a la consolidación de la independencia y la autodeterminación nacionales.

De este enfrentamiento entre pueblo y oligarquía han dependido, a su vez, los términos y el alcance con que se han desplegado a lo largo del siglo las distintas fases del conflicto entre Panamá y
Estados Unidos. Al respecto, resulta notorio el hecho de que cada uno de los momentos decisivos de ese conflicto conforme un verdadero ciclo, en el que se suceden:

a) Una prolongada acumulación de tensiones sociales, que desemboca en una inestabilidad política creciente (en 1925-30; $1947-50$ y 1964-67).

b) Golpes de Estado -en 1931, 1951 y 1968-, que rompen la institucionalidad oligárquica y abren espacio a iniciativas de desarrollo del Estado nacional que lo van dotando de una creciente capacidad de representación del interés general de la nación, así como de capacidades cada vez más complejas y de creciente autonomía relativa en materia ideológica, represiva, económica y social.

c) La apertura de procesos de negociación entre Panamá y Estados Unidos que -en 1936, 1954 y 1977-dan lugar a mo-

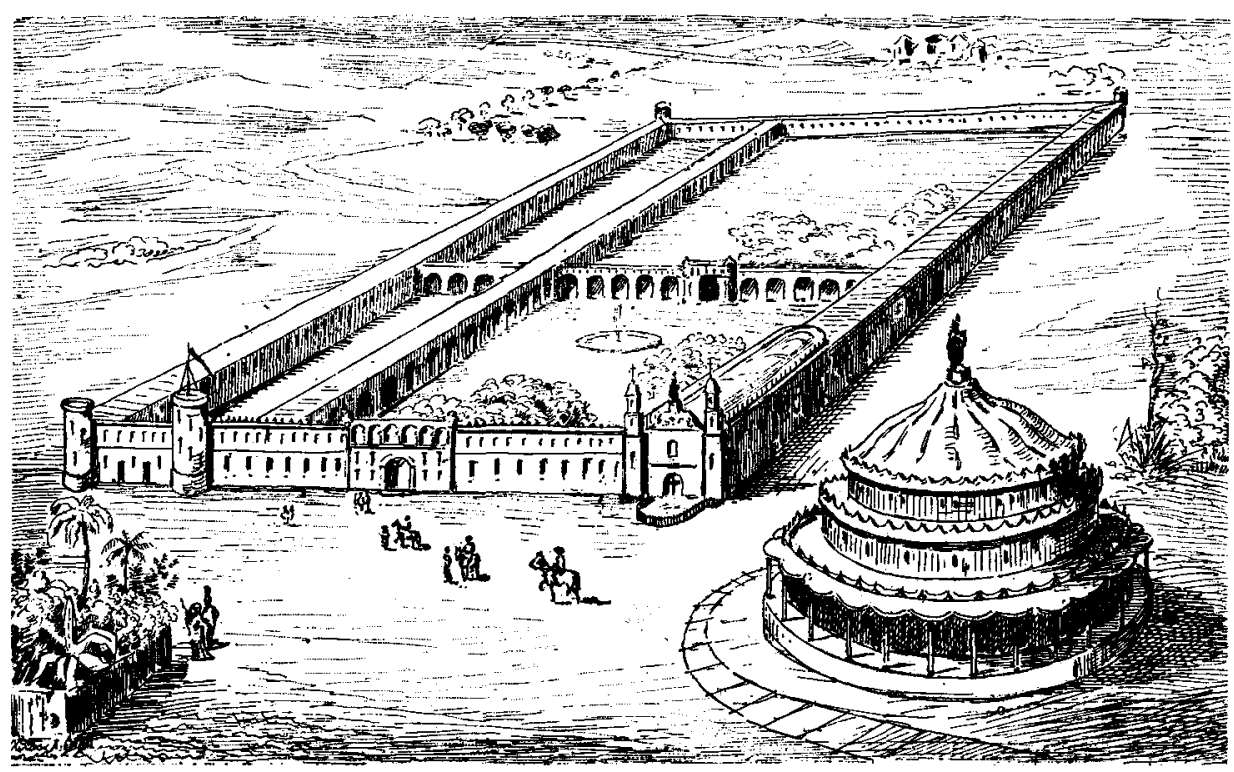


dificaciones del Tratado Hay-Buneau Varilla de 1903, que sentó las bases fundamentales de relación entre ambos Estados y normó las modalidades originales de articulación entre el enclave canalero y la sociedad nacional.

d) Un periodo de bonanza económica sustentada en mayor participación panameña en las posibilidades de acumulación asociadas al enclave, aprovechada, sobre todo, por las fracciones mejor articuladas al capital extranjero de una oligarquía cuyas estructuras fundamentales de dominación permanecen intactas en el proceso.

e) El cierre del ciclo mediante procesos electorales que legitiman la nueva correlación de fuerzas en el seno de los sectores dominantes, permiten una plena recomposición de la hegemonía oligárquica en el Estado e inauguran periodos de estabilidad relativa, siempre amenazada por los mismos sectores atrasados de la oligarquía y por amplios sectores populares sistemáticamente marginados de los beneficios de la bonanza económica, cuya confluencia en etapas deagotamiento deésta, constituyeel punto de partida para un nuevo periodo de crisis.

Lo que describimos constituye, por supuesto, una tendencia general y en ningún caso un proceso mecánico de eterno retorno. Tal tendencia, por el contrario, ha estado relacionada siempre con los cambios que el capitalismo en su desarrollo ha ido imponiendoa cada uno de los polos del conflicto interno al que hacemos referencia $y$, por tanto, a las modalidades de relación entre ambos en el interior del proceso de formación nacional. Tales cambios, a su vez, induyen los relativos al desarrollo del propio Estado nacional, de sus instituciones políticas, de sus aparatos ideológicos y, por supuesto, de sus órganos de represión. Es precisamente ese desarrollo global, puesto en relación además con las transformaciones del contexto internacional a lolargo de la década de 1980, el elemento a examinar para intentar explicarnos las razones de que el tipo de ciclo descrito para los casos de 1931-36 y 1951-54 no operara en iguales términos para el periodo $1977-84$ y, por el contrario, desembocara en los hechos del 20 de diciembre de 1989.

\section{El PAIS}

Con 77 kilómetros cuadrados y una posición geográfica privilegiada para asistir al comercio mundial, Panamá ha llegado a ser un país poblado por 2200000 habitantes, de los cuales cerca de $40 \%$ vive en la pobreza, mientras $20 \%$ de más altos ingresos concentra $60 \%$ de la riqueza nacional. Tales desigualdades se encuentran intimamente asociadas al hecho de que, desde el siglo XVI y con una continuidad singular en América Latina, la economía del país ha estado organizada en función del tránsito de mercancías, capitales y personas entre los océanos Atlántico y Pacífico y subordinada, además, a los intereses de las potencias que hegemonizan el mercado mundial.

Resultado de ello ha sido un modelo de crecimiento económico que cabe denominar transitista, potenciado en este siglo por la construcción del canal y por la posterior instalación en el país -desde la década de 1950 y sobre todo desde la de 1970-, de una plataforma de servicios transnacionales en cuyo funcionamiento destacan, entre otros, un centro financiero internacional, la zona de libre comercio de Colón y un oleoducto construido para el trasiego del petróleo de Alaska a la costa este de Estados Unidos. La estructura económica 
de dicho modelo se caracteriza por un desmesurado predominio de su sector terciario, que aporta entre 70 y $80 \%$ del PIB del país.

Al propio tiempo, los sectores agrícola.e industrial sufren un constante rezago y las deformaciones derivadas de su orientación dominante en el mercado externo y del consumo de los sectores nacionales de mayores ingresos. Esa situación se agrava, además, por la ausencia de mecanismos que estimulen y permitan la transferencia de los excedentes generados en el sector de comercio y servicios, a esos campos de actividad económica. Tales excedentes, por el contrario, tienden a invertirse en el mismo sector que los genera y-sobre todo a partir del agotamiento de la capacidad de expansión del mismo desde fines de la década de 1970, cuando el PIB nacional alcanzó un tope del orden de los 4500 millones de dólares-, a ser desviados en proporciones cada vez mayores hacia actividades especulativas e improductivas.

Esta situación, a su vez, da lugar a una extraordinaria concentración del poder económico que acarrea severas consecuencias sociales y políticas para el país, sometiéndolo a las condiciones de precaria estabilidad que subyacen tras los ciclos a que antes hacíamos referencia. En efecto, estudios realizados por académicos panameños ${ }^{1}$ revelan que, de una Población Económicamente Activa (PEA) de 750000 personas, 600000 son trabajadores-de los cuales entre 150 y 200000 tienen algún grado de organización-, y 150000 son propietarios de medios de producción, en su inmensa mayoría

\footnotetext{
${ }^{2}$ Marco Gandásegui, La demoç̧acia en Panamá, Editorial Mestiza/Universidad Autónoma Metropolitana, México, 1989; William Hughes e Iván Quintero, ¿Quiénes son los dueños de Panamå, CEASPA, Panamá, 1987.
}

pequeños $y$, en menor proporción, medianos. Sin embargo, las características del modelo de crecimiento transitista determinan la existencia, dentro de ese sector de propietarios, de un grupo de poco más de 100 grandes empresarios que -a través de una densa red de entidades financieras, comerciales e industriales estrechamente vinculadas al capital transnacional-, controlaban para fines de la década de 1980 cerca de $75 \%$ de la riqueza nacional.

En tales términos, puede afirmarse que una ínfima minoría social se transforma, en virtud de su poderío económico, en una virtual mayoría política, cuyas luchas fraccionales -enmarcadas en la permanente confrontación con los sectores populares y capas medias, y por la lucha por sus propios intereses en su relación con el Estado norteamericano-, conforman una situación en la que:

La historia política panameña registra sólo una experiencia donde la oposición triunfa en elecciones presidenciales y el poder es transferido sin conflicto al ganador. Es el caso de las elecciones de 1960 cuando el candidato liberal derrota al candidato oficial de la Coalición Patriótica Nacional. En la gran mayoría de los casos los candidatos opositores se han retirado de la contienda bajo el pretexto de no existir condiciones para la realización del torneo electoral. En otros casos, una vez celebrado el evento, el candidato opositor acusa a su contendor de abusos y fraude. ${ }^{2}$

Resulta evidente, asi, a todas luces, que el transitismo sólo puede servir de base material a una democracia restringida a las necesidades de la lucha por el control del Estado entre las fracciones de la clase dominante. A ello concurren además otras doscircunstancias: una, que

$$
{ }^{2} \text { Ibid., p. } 11 .
$$



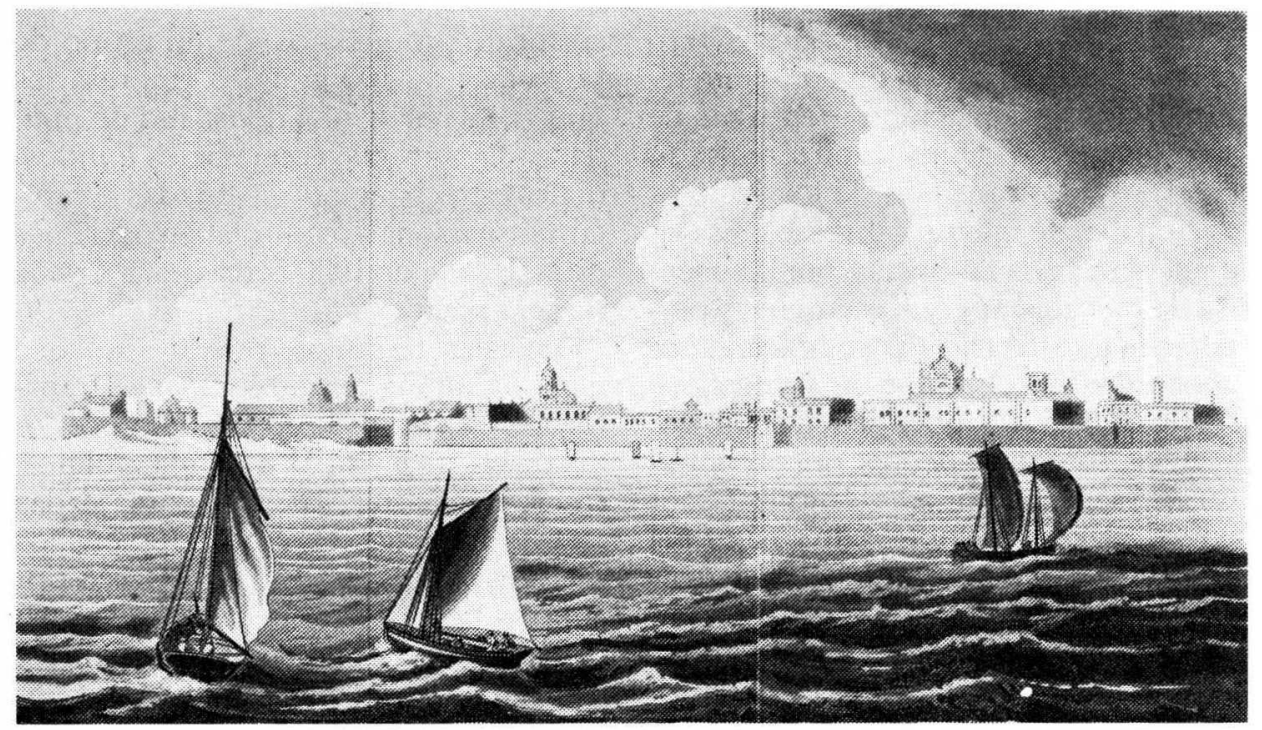

la tendencia a la concentración del poder en ese sector social opera, además, en términos de la desconcentración permanente de las posibilidades de construcción y ejercicio de un verdadero poder alternativo por parte de los sectores subordinados, constantemente sujetos al efecto desorganizador y desagregador que se deriva del carácter atrasado y heterogéneo de la estructura socioeconómica. Otra, que la naturaleza misma de esa estructura, centrada en el eje compuesto por el enclave de capital monopólico del Estado norteamericano y en el del capital financiero transnacional, convierte a los representantes de ambos $-y$ en particular a las fuerzas armadas de Estados Unidos- en actores directos de la política nacional.

Los términos en que esto último ocurre, sobre todo en lo que se refiere al enclave canalero y al Departamento de Defensa de Estados Unidos, han sido hasta ahora poco estudiados. No se trata, en todo caso, únicamente de las posibilidades que la situación descrita abre para la participación del Estado norteamericano y sus fuerzas armadas en la política panameña. Además de eso, se trata del papel que el enclave ha desempeñado en el desarrollo de la vida cultural y política que ha determinado el proceso de formación de la nación y su Estado.

Al respecto puede afirmarse, por ejemplo, que la presencia del enclave no sólo bloquea la posibilidad de un desarrollo más armónico, racional y moderno -en el mejor sentido del término-, de la economía, de la sociedad y de la política panameña. Además, pervierte de modo peculiar -en el sentido que sugiere el poeta José de Jesús Martínez al señalar que "una economía de servicios produce una mentalidad de sirvientes"- las aspiraciones y percepciones del sector dominante en esa estructura $-y$, por exten- 
sión, las de su clientela política más inmediata- en lo que respecta a problemas fundamentales de la formación nacional. Tales son algunos de los factores que, llevados a su máxima expresión, contribuyen a explicar la crisis de 198489 , sus consecuencias inmediatas y las perspectivas que de alli se desprenden para el futuro de Panamá.

\section{LA CRISIS}

El enclave canalero y sus modalidades de articulación con la sociedad panameña constituyen el caso extremo -no por ello excepcional- de las relaciones de dependencia que definen el desarrollo histórico del conjunto de la región latinoamericana. En este sentido, la invasión extranjera y el golpe de Estado del 20 de diciembre de 1989 son parte de la crisis general por la que atraviesa América Latina, en cuyo seno cabe hacer el esfuerzo por comprender la especificidad de lo ocurrido en Panamá.

Teórica e idealmente, las negociaciones que condujeron al Tratado TorrijosCarter de 1977 debieron abrir camino en el interior de la sociedad panameña, a un nuevo proceso de legitimación electoral de la hegemonía, lograda en la década de 1970 por la fracción de la oligarquía local más vinculada al capital financiero transnacional que a su vez expresaba la forma extrema de desarrollo del modelo transitista de crecimiento económico. No ocurrió debido a la concurrencia de diversos factores que advertían el fin de aquella etapa de la vida nacional desplegada a través de los ciclos de crisis-negociación-estabilización de 1931-36 y 1951-54.

De entre esos factores que alteraron de manera tan completa el sentido y la función en la hora de las elecciones en
Panamá cabe mencionar los siguientes:

a) A diferencia de cualquiera de las negociaciones anteriores, la que culminó en los Tratados Torrijos-Carter no desembocó en un periodo de bonanza económica para Panamá, sino en el ingreso del país a la crisis general desplegada en América Latina a partir de 1980. En lo económico, para 1984 -año de las elecciones en que teóricamente debió culminar una nueva edición del ciclo histórico antes descrito-, Panamá ingresó al círculo de países latinoamericanos que pagaron, por concepto de servicio a su deuda externa, un monto superior al de los nuevos créditos que recibieron. En lo social y lo político, el pais ingresó desde 1983 al mismo proceso de incremento de tensiones y polarización de posiciones que desde entonces caracterizan a la región, que a su vez abrió paso a una creciente injerencia de Estados Unidos en los asuntos internos del país, en el marco de una situación regional caracterizada por el desmantelamiento progresivo de las actitudes y mecanismos de solidaridad surgidos en la década anterior.

b) A diferencia de los ciclos anteriores, en aquél de la década de 1970 el Estado nacional conoció formas de desarrollo que lo dotaron de una autonomía relativa sin precedentes en su historia, que dificultó en grado extremo las posibilidades de la oligarquía para reconstruir su poder sobre el mismo. Tres factores de este proceso deben ser mencionados aquí:

1. El desarrollo del gasto público y del poderoso sector estatal de la economía -a cuenta del endeudamiento externo y no de las transformaciones estructurales en el modelo de crecimiento transitista-, que permitieron al Estado desplazar al enclave canalero como principal factor de generación de demanda en la econo-

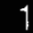

6

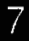


mía interna a lo largo de las décadas de 1970 y 1980 , lo que a su vez estrechó las relaciones de dependencia respecto al mismo en amplios sectores de capas medias y una nutrida burocracia.

2. La conducción de ese proceso de desarrollo estatal por sectores nacionalistas de capas medias en alianza con fracciones modernizantes de la oligarquía financiera, que condujo al fortalecimiento sin precedentes de una burguesía burocrática que, en virtud de su control de las instituciones y mecanismos de mediación política del Estado, pudo ofrecer una feroz resistencia a lo que en otras circunstancias hubiera sido una restauración "espontánea" del poder político de la oligarquía sobre el Estado.

3. El desarrollo de una fuerza armada nacional -surgida justamente a partir de la renuncia de Estados Unidos a su derecho unilateral de intervención por vía militar en los asuntos internos de Panamá en 1936-, que como Policía Nacional había ejecutado el golpe de Estado de 1951 para convertirse en Guardia Nacional en 1953, ejecutar como tal al golpe de Estado de 1968, encabezar la dirección del Estado y las negociaciones con Estados Unidos en la década de 1970 y, convertida en Fuerzas de Defensa a partir de 1983, actuar como factor fundamental de poder en el Estado hasta su destrucción por el ejército nortëamericano en diciembre de 1989. Estrechamente vinculada a la burguesía burocrática, y aburguesada ella misma hasta el tuétano en sus mandos a lo largo de las décadas de 1970 y 1980, la fuerza armada panameña encarna el proyecto de un desarrollo capitalista autónomo, en ausencia de una verdadera burguesía nacional en Panamá, que necesariamente suponía el control del enclave canalero por un Estado nacional incompatible con los intereses hegemónicos de Estados Unidos. c) Finalmente, y sobre todo, debe tomarse en cuenta la naturaleza misma de lo negociado en los Tratados TorrijosCarter que, a diferencia de los de 1936 y 1954, implicaban la total transferencia al Estado panameño del enclave canalero $y$, con ello, convertían a la naturaleza misma de ese Estado en un problema político y de seguridad para Estados Unidos. En efecto, los tratados de 36 y 54 perfeccionaron-pero no alteraron en lo fundamental-, la articulación entre la economía del enclave y la del resto del país. Al abrir el primero de esos tratados, el mercado del enclave a la producción nacional y capturar, el segundo, para la burguesía comercial panameña, los salarios de los trabajadores panameños del canal y las bases militares -que, como empleados federales del gobierno de Estados Unidos, venden su fuerza de trabajo a precios correspondientes a los de aquel país-, ${ }^{3}$ tales negociaciones ahorraron a los sectores dominantes de Panamá la necesidad de emprender cambios estructurales que -por limitados o mediatizados que hayan sido- exigieron a otras burguesías latinoamericanas la ampliación de sus mercados internos.

Puede afirmarse, así, que la lucha fundamental de la oligarquía panameña en lo que al problema del mercado se refiere se orientó -hasta la década de 1970-, a capturar para sí el del enclave antes que a desarrollarlo en el conjunto de la economía nacional. Esto, a su vez, contribuye a explicar la persistencia de la hegemonía transitista en el conjunto de la estructura socioeconómica, y de las

${ }^{3}$ Es útil señalar, por ejemplo, que un bombero recién ingresado al servicio de la comisión del canal obtiene un salario superior a los 1000 dólares mensuales, que en la economia panameña corresponde a ejecutivos de nivel medió del sector privado. 
conductas y la cultura políticas correspondientes. De allí además, en buena medida, deriva la capacidad de la oligarquía para recomponer su poder político que, después de cada negociación con el Estado norteamericano, siempre permaneciera inalterada la naturaleza esencial del vinculo sociedad-enclave establecido a partir de 1903.

Los tratados de 1977, con su programa de reversión por etapas de la totalidad del enclave y sus actividades para la soberanía panameña, crearon una situación que hacía insostenible la continuidad de aquel vínculo. Dentro de la lógica del transitismo, ello planteaba dos opciones en lo que a Panamá y su estado se refería. La primera consistía en modificar la naturaleza del enclave poniéndolo al servicio del desarrollo integral del país: ésa era la postura que se expresaba en las formulaciones teóricas más avanzadas del torrijismo, aunque no en lo general de sus prácticas políticas desde fines de la década de 1970.

La nacionalización del enclave, en efecto, suponía dos tareas que encontraban una singular resistencia en las estructuras, los intereses creados y las prácticas políticas inherentes al transitismo, por un lado, convertir al enclave en parte del sector estatal de la economía; por otro, iniciar las transformaciones estructurales que el conjunto de la sociedad requería para adquirir la capacidad de asimilar el potencial del enclave a su desarrollo integral. Si lo primero suponía excluir a la oligarquía y a las transnacionales del control directo de las posibilidades de acumulación que ofrecían el canal y sus instalaciones, lo segundo significaba desarticular las bases del poder oligárquico en el conjunto de la sociedad panameña $y$, con ello, reducir severamente la capacidad de influencia directa del imperialismo en la vida política del país.
La segunda de las opciones que mencionamos, por el contrario, consistía en modificar la naturaleza de la sociedad y el Estado nacionales, eliminando aquellos rasgos adquiridos en su proceso de formación que de uno u otro modo entraban en conflicto con la función de subsidio a la economía norteamericana y con los intereses geopolíticos de Estados Unidos que caracterizaban la naturaleza del enclave desde su creación. Esta opción, correspondiente a los intereses del Estado norteamericano y de la oligarquía panameña, no excluye por cierto la posibilidad de que el canal revierta a la soberanía de Panamá, siempre y cuando ésta tenga como su representante formal a un Estado nacional subordina do al poder de los aliados tradicionales de Estados Unidos en el país.

La primera propuesta formal en favor de esta opción se produjo en 1987, ya en medio de la primera fase de la confrontación entre Panamá y Estados Unidos que culminaría en el golpe de Estado de diciembre de 1989. En una conferencia anteel Club Rotario de Panamá, el empresario Fernando Manfredo -torrijista en la década de 1970, y como tal designado primer subadministrador panameño en la comisión del canal-, planteó la necesidad de que el país se preparara para hacerse cargo de la vía interoceánica modificando todas sus normas administrativas y su legislación social y económica hasta hacerlas compatibles con las que regían en el enclave. A su auditorio no pareció extrañarle que, por esa vía, el país terminaría por convertirse en una dependencia sui generis del gobierno de Estados Unidos.

En 1988, ya en el marco de la agresión abierta de Estados Unidos contra Panamá, el Documento de Santa Fe IIse refería al tema con la brutal sinceridad que caracteriza a la extrema derecha norte- 
americana, sintetizando en los siguientes términos lo que sería el programa político del golpe de Estado que el ejército norteamericano en Panamá ejecutaría el siguiente año:

La expulsión de (Manuel Antonio) Noriega y la realización de elecciones no serán suficientes para instaurar un régimen democrático en Panamá. Estados Unidos tendrá que concentrarse en los asuntos atinentes a un régimen democrático: la reforma de las FDP (Fuerzas de Defensa de Panamá), el apoyo a un poder judicial independientey la restauración de la economía, serán esenciales... Las leyes bancarias tendrán que ser modificadas para impedir que el país se hunda una vez más en la corrupción basada en el cártel del narcotráfico. La Constitución panameña deberá ser modificada para permitir la extradición de ciudadanos panameños culpables de crímenes en terceros países... una vez que esté en el poder un régimen democrático, Estados Unidos y Panamá deberán comenzar a planificarseriamente la adecuada administración del canal... Al mismo tiempo, deberán iniciarse las discusiones en torno a una defensa realista del canal después del año 2000. Estas pláticas deberán incluir la retención, por parte de Estados Unidos, de un número limitado de instalaciones en Panamá (principalmente la base aérea de Howard y la estación naval de Rodman), para una adecuada proyección de fuerza en el hemisferio occidental.

Estas cuestiones no han sido consideradas y deberian serlo para principios de 1990 , si es que han de ser asegurados los intereses nacionales de Panamá y Estados Unidos para el próximo siglo. ${ }^{4}$

Enfrentado a estas dos opciones, el régimen panameño intentó evadirlas mediante una política canalera que, si por un lado enfrentó las consecuencias

${ }^{4}$ Enriqueta Cabrera (comp.), En respuesta a Santa Fe II, El Día en Libros, México, 1989, pp. 216-227. Las cursivas son mías.

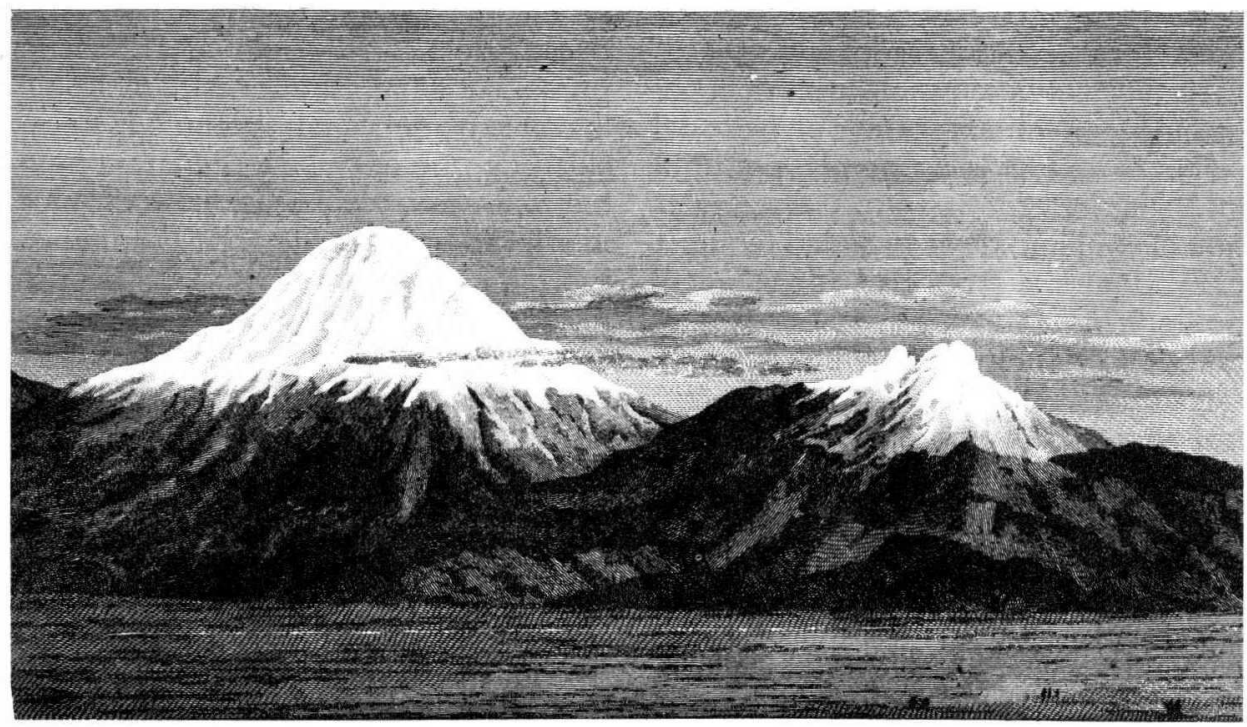


extremas de la segunda, por otro no asumió la necesidad de transformaciones estructurales que exigía la primera. En cambio, se procuró privilegiar el acceso a las actividades del enclave que revertían la soberanía panameña a la burguesía burocrática aliada a las Fuerzas de Defensa, enmascarando las limitaciones de esta salida mediante un discurso que presentaba a las fuerzas armadas como representantes del interés general de la nación y como protagonistas fundamentales de la confrontación entre ésta y Estados Unidos, por encima de toda participación de los sectores populares que se sustentara en un reconocimiento efectivo de los intereses y aspiraciones de éstos.

Tomando en cuenta este conjunto de circunstancias, se puede afirmar que $l a$ creación de las condiciones que condujeron a la derrota politica del torrijismo, que precede y explica su derrota militar de diciembre de 1989, se inició a partir del fracaso de las elecciones de mayo de 1984 como medio para legitimar el orden de cosas surgido de las negociaciones que culminaron en los Tratados Torrijos-Carter. En esas elecciones, los organismos de dirección político-militarcreados por el torrijismo -en particular el Estado Mayor de las Fuerzas de Defensa y la cúpula dirigente del Partido Revolucionario Democrático-, decidieron invertir el caudal de apoyo popular acumulado por el general Torrijos en la década anterior en favor de una alianza con la fracción financiera de la oligarquía panameña y sectores entonces considerados "pragmáticos" en la administración Reagan. De ello resultó la llegada a la presidencia de la república de Nicolás Ardito Barletta y Eric Del Valle, promotores de un programa de ajuste estructural económico y, por extensión, de las relaciones entre Panamá y Estados Unidos con vistas a satisfacer las aspiraciones de este último en lo relativo a la ejecución de los Tratados y a la defensa de sus intereses geopolíticos en América Central.

Esos hechos marcaron un punto de viraje en la relación del torrijismo con el movimiento nacional-popular en Panamá. En efecto, ante la disyuntiva de enfrentar la crisis, profundizando y consolidando el programa de reformas que había permitido al general Torrijos acumular aquella base de apoyo popular -enfrentando con ello la resistencia de la oligarquía y las presiones del imperialismo-, o desmantelar lo alcanzado en ese programa dentro de una estrategia de conciliación con los adversarios tradicionales del torrijismo, se optó por lo segundo. Tal decisión dio lugar a que, antes de que se hubiera logrado estabilidad alguna en el país, se crearan las condiciones necesarias para aquella confluencia del descontento popular con el de los sectores más tradicionales de la oligarquía, que había sido ya el detonante de los más importantes periodos de crisis política en la historia nacional. Las consecuenciasnose hicieron esperar.

Para fines de 1984, los primeros intentos para aplicar la política de ajuste estructural desembocaron en una franca ruptura de las capas medias urbanas con el régimen. Para mediados de 1985 , se producía el derrocamiento de Barletta, justificado en nombre de la impopularidad de su política de subordinación al FMI y al Departamento de Estado. Para marzo de 1986, el paquete legislativo exigido por el FMI era aprobado por la mayoría oficialista de la Asamblea Legislativa, en medio de protestas de sectores empresariales de la agricultura y la industria, y de la represión a una huelga general convocada con notable éxito por el movimiento obrero, que contó con amplio a poyo de otros sectores populares. 
Para fines de 1986, la fuerza armada y el aparato político-burocrático se habían convertido en las únicas bases de sostén del régimen. Ese fue el momento escogido por la administración Reagan para solicitar al general Noriegà su ayuda en la agresión norteamericana contra Nicaragua, cuya negativa sirvió de punto de partida al proceso de confrontación abierta de Estados Unidos contra Panamá que se iniciaría a mediados de 1987.

Para esa confrontación, el estado norteamericano iba a encontrar un terreno abonado en el vacío ideológico y de conducción política creado por la derrota del movimiento popular en 1986 y una ruptura entre el régimen y sus aliados de la década anterior. Ese vacío fue llenado por la autodenominada Cruzada Civilista Nacional, surgida de los gremios empresariales, avalada por la jerarquía católica y orientada en lo político por la embajada norteamericana y los partidos de la derecha oligárquica que, finalmente, llegarían al poder -al cabo de 5000 muertos y 4000 millones de dólares en pérdidas para la economía nacional-, el 20 de diciembre de 1989, en calidad de administración nativa del ejército extranjero de ocupación.

\section{(ALGUNAS) LECCIONES Y PREVISIONES}

Forzado por las circunstancias para elegir entre la soberanía y la democracia, el pueblo panameño terminó viéndose privado de ambas y convertido en objeto de un protectorado extranjero. Lo abstracto de esas categorias políticas, sin embargo, dificulta la comprensión de lo concreto dela circunstancia que se busca explicar con ellas.

Lo acaecido en Panamá comprueba, simplemente, que la soberanía popular -entendida justamente como base de la soberanía nacional-es incompatible con una democracia restringida al papel de escenario de las luchas fraccionales en el seno de una clase dominante identificada con intereses que por esencia son antinacionales y antipopulares. A ello, y no a otra cosa, se deben la inestabilidad de la democracia en Panamá, lo azaroso y limitado del papel que en ella han cumplido los procesos electorales, y las constantes contradicciones y conflictos que han animado la función y relación de aquélla con el proceso más amplio y decisivo de formación de la sociedad y el Estado nacionales.

Tales contradicciones y conflictos entre esa democracia y la lucha nacional por la soberanía y la autodeterminación, culminaron en la derrota definitiva de la primera entre 1984 y 1989 , en lo interno primero y por medio de la invasión extranjera después. Esa derrota cierra toda una etapa de la historia de Panamá: aquella de la contradictoria coexistencia entre el proceso de formación nacional y el enclave canalero. Esta etapa ha concluido con la derrota del Estado transitista panameño por el norteamericano, que hoy pretende convertir a nuestra nación en un mero apéndice del enclave extranjero, supervisado por los "contralores" designados por los departamentos de Estado y Defensa en cada institución pública del país ocupado por las tropas del Comando Sur, y administrado deacuerdo a los lineamientos esbozados en el documento de Santa Fe II.

De este modo, y precisamente en su fracaso, afloran con nitidez los rasgos fundamentales de la verdadera naturaleza de la democracia existente en $\mathrm{Pa}$ namá hasta diciembre de 1989: el rey, finalmente, está desnudo. Sus ropas, en todo caso, no desaparecieron de golpe: fueron desgarradas paso a paso a lo largo de aquella etapa de nuestra historia que, 


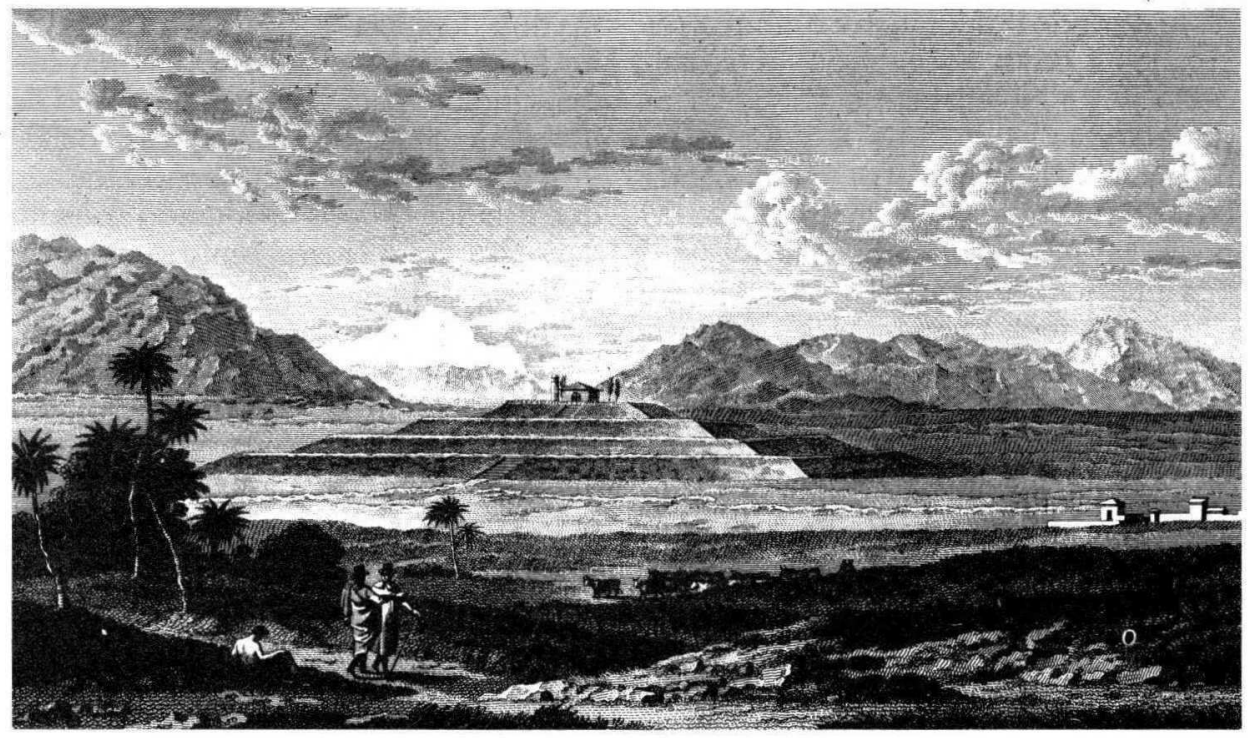

de 1931 en adelante, vio a las capas medias asumir un liderazgo ideológico y político cada vez más importante en el proceso de formación nacional, en alianza con sectores de la oligarquía interesados en potenciar el transitismo sin transformarlo.

En el ejercicio de ese liderazgo, y en permanente conflicto con la institucionalidad creada por la oligarquía para el servicio de sus propias necesidades, las capas medias hicieron importantes aportes a la consolidación de una cultura y una identidad nacionales, así como a la incorporación en la vida política del país de aquellas reivindicaciones populares que no parecían incompatibles con la preservación del modelo de crecimiento transitista. La posibilidad del ejercicio de ese liderazgo sin embargo, llegó a su límite extremo con el agotamiento de la capacidad de expansión del modelo de crecimiento. De este modo, la alianza entre las capas medias nacionalistas y la fracción modernizante de la oligarquía llegó a su término y se fragmentó bajo el impacto de la crisis en la década de 1980 , dejando al país enfrentado a la tarea imposible de recomponer su estabilidad sin la verdadera participación de los sectores populares y mayoritarios de la nación.

Lo imposible de la tarea, en todo caso, no venía del país mismo. De no haber adoptado la crisis el curso determinado por la intervención y la invasión extranjera, hubiera podido esperarse que la ruptura entre las capas medias y la oligarquía abriese paso a un nuevo liderazgo nacional de corte más definidamente popular y de orientación efectivamente democrática. Ese otro curso -que en circunstancias como la de Brasil, para utilizar una contraposición extrema, ha llevado al surgimiento del Partido de los Trabajadores- hubiera podido incluso parecer "natural" de no haberse visto bloqueado por la intervención extranjera en la crisis, que estimuló la militarización de la vida política del país, convertida por la conducción político-militar del torrijismo en la última tabla de salvación 
de su poderío bu rocrático y sus intereses creados a costa, sobre todo, del abandono de lo que habían sido sus bases populares.

Es notable, sin embargo, que con toda la impopularidad del régimen derrocado por la invasión extranjera, sus adversarios internos nollegaran jamás a plantear una verdadera amenaza a su sobrevivencia política. Ocurre, en efecto, que la verdadera fuerza motriz de la historia panameña se encuentra $-y$, por ahora, aguarda-en aquellossectores populares que el torrijismo incorporó a la vida nacional y que luego procuró mediatizar y desmovilizar. En este sentido puede decirse que la invasión y el golpe militar de diciembre de 1989 tuvieron, en medio de todos sus enormes males, la virtud de liberar a esos sectores populares del enorme peso muerto de la burocracia estatal y del régimen de partido de la democracia oligárquica, creando así la condición imprescindible para que la polarización social creada por la crisis empiece a transformarse en verdadera polarización política, destinada a desplegarse en formas nuevas por las que habrá de discurrir el conflicto de la historia panameña, aún pendiente de solución.

No puede adelantarse en este momento el detalle de lo que serán esas formas. En Panamá, como dijera Martí de la América Latina hace más de un siglo, "las especies luchan por el dominio en la unidad del género". Sin embargo, es un becho que el contenido de las aspiraciones de ese género apunta a un modelo alternativo de sociedad que necesariamente habrá de ser: nacional por lo popular; popular por lo democrático, $y$ democrático por lo revolucionario. Y por todo ello será además, latinoamericanista y antimperialista. En efecto, únicamente en esos términos podrá el pueblo panameño resolver, a un tiempo, el proble- ma de la democratización del país a través de la creación de la base material imprescindible para el funcionamiento de una democracia de amplia base social.

De momento, es un hecho también que Estados Unidos ha logrado consolidar su hegemonía en el istmo a cuenta de la desestabilización extrema de la sociedad panameña que, con toda probabilidad terminará por poner en jaque dicha hegemonia, en términos mucho más complejos y peligrosos para los intereses norteamericanos en Panamá. El costo social del programa de consolidación de la dependencia panameña que lleva a cabo el gobierno surgido de la invasión es tal, que sólo puede ser ejecutado por medios dictatoriales. Pero, al mismo tiempo, es tal el aislamiento interno de la oligarquía representada en dicho gobierno, que sólo puede ejercer esa dictadura a cuenta del respaldo de las fuerzas armadas norteamericanas.

Puede decirse, así, que la administración Bush ha optado - a sabiendas o nopor empantanarse politicamente en Panamá: pierde, si debe hacerse cargo de manera permanente del gobiemo del país, y pierde también si opta por desentenderse del gobierno quele ha impuesto al país. Entretanto, fuerzas y realidades políticas nuevas -que entrañan la perspectiva de desafios también nuevos para Estados Unidos y sus aliados- van tomando forma en Panamá. De la rapidez con que lo hagan, y de su maduración como nueva alternativa para la conducción política del país, dependerá en una medida importantísima lo que tarde $\mathrm{Pa}$ namá en superar efectivamente la crisis por la que viene atravesando desde hace casi un decenio. De ello dependerá, también, que la hora de las elecciones llegue a ser, en Panamá, la de la legitimación definitiva de nuestro derecho a existir como nación. 